\title{
Artefatos de contabilidade gerencial, organização sem fins lucrativos e características contingenciais
}

\section{Management Accounting Artifacts, Non-profit Organization and Contingency Features}

\author{
JOÃO GABRIEL VASCONCELLOS GODOY \\ Universidade do Estado de Santa Catarina \\ FABIANO MAURY RAUPP \\ Universidade do Estado de Santa Catarina
}

\section{RESUMO}

O artigo apresenta os resultados do estudo que teve por objetivo analisar o uso de artefatos de contabilidade gerencial em uma organização sem fins lucrativos de Florianópolis, Santa Catarina, à luz de características contingenciais. A pesquisa é exploratória, realizada por meio de um estudo de caso, o Instituto Vilson Groh, uma associação de entidades sociais. A coleta de dados deu-se por meio de dados secundários, observação e entrevista. A partir da identificação do uso de artefatos de contabilidade gerencial no conteúdo da entrevista, seguiu-se à relação entre o uso destes artefatos e características contingenciais da organização. A análise da relação entre características contingenciais e a adoção e uso dos artefatos culminou com a produção de conclusões acerca do caso estudado, as quais podem ser transformadas em questionamentos ou hipóteses para pesquisas futuras: atividades de avaliação subjetiva levam à adoção de artefatos de controle como medidas de desempenho; a adoção de artefatos de contabilidade gerencial por meio do isomorfismo normativo é potencializada pela centralização da estrutura organizacional; e o incentivo à capacitação dos colaboradores da organização potencializa a influência das comunidades de prática na adoção de artefatos pela organização.

Palavras-chave: Artefatos de contabilidade gerencial. Organização sem fins Lucrativos. Características contingenciais. 


\section{Abstract}

The article presents the results of the study that aimed to analyze the use of management accounting artifacts in a nonprofit organization of Florianópolis, Santa Catarina, in light of contingency characteristics. The research is exploratory, carried out through a case study, the Vilson Groh Institute, an association of social entities. Data collection took place through secondary data, observation and interview. From the identification of the use of management accounting artifacts in the interview content, the relationship between the use of these artifacts and contingency characteristics of the organization was followed. The analysis of the relationship between contingency characteristics and the adoption and use of artifacts culminated in the production of conclusions about the case studied, which can be transformed into questions or hypotheses for future research: evaluation activities subjectivity lead to the adoption of control artifacts as performance measures; the adoption of management accounting artifacts through normative isomorphism is enhanced by the centralization of the organizational structure; and the incentive to the training of the organization's employees enhances the influence of communities of practice on the adoption of artifacts by the organization.

Keywords: Management accounting artifacts. Non-profit organization. Contingency features.

\section{CONSIDERAÇões INICIAIS}

As práticas de gestão não têm sido implementadas pelas organizações da sociedade civil na mesma velocidade de seu crescimento (SOLDEVILA; OLIVEIRAS, 2000). Uma possível causa é a visão empresarial existente nos estudos da contabilidade. Iudícibus $(2012$, p.8) entende a contabilidade como "linguagem universal dos negócios". É possível perceber a partir desta linguagem que a contabilidade, assim como a administração, está eminentemente voltada para o estudo das empresas (BÖHM, 2006). Entretanto, a análise de eventos econômicos e financeiros é necessária aos mais variados tipos de organização, visto que esta dimensão, mesmo não constituindo um fim para muitas organizações, é comumente um meio para alcançar objetivos organizacionais (FRANÇA FILHO, 2007). 
Considerando este contexto, o estudo tem como tema a utilização de artefatos de contabilidade gerencial por entidades sem fins lucrativos. Para Olak e Nascimento (2010), mesmo sendo embrionárias as práticas contábeis particulares às organizações sem fins lucrativos, por não possuírem demandas tão rigorosas como as empresas, possuem liberdade para adotar artefatos mais adequados às necessidades gerenciais. Questiona-se, portanto, como os artefatos de contabilidade gerencial são adotados e utilizados por uma organização sem fins lucrativos?

Para tanto, o artigo apresenta os resultados do estudo que teve por objetivo analisar o uso de artefatos de contabilidade gerencial em uma organização sem fins lucrativos de Florianópolis, Santa Catarina, à luz de características contingenciais. Dois são os conceitos necessários para abordar as questões levantadas anteriormente, sejam eles os artefatos de contabilidade gerencial, que são parte do objeto desta pesquisa, e a abordagem contingencial dos estudos organizacionais, lente eleita para a análise desta parte da realidade. Tais questões são apresentadas na próxima seção.

O estudo se propõe a contribuir para a compreensão de quais características organizacionais estão relacionadas ao uso de quais artefatos, permitindo que gestores adotem artefatos mais adequados à sua gestão, bem como acadêmicos pesquisem melhores formas de abordar as demandas destas organizações. Conforme já apresentado, o desenvolvimento de artefatos de contabilidade gerencial para auxiliar a tomada de decisão tem-se voltado tradicionalmente para empresas (BÖHM, 2006). Aliado a isso, um momento de estruturação para as organizações sem fins lucrativos tende a aumentar a demanda destas organizações por estes tipos de artefatos.

Neste ínterim, além de explorar as noções de artefatos de contabilidade gerencial e da abordagem contingencial, cabe contextualizar a organização que será estudada, e definir o que se deseja alcançar. As próximas seções conterão estes itens, para então ser possível prosseguir com a apresentação dos resultados e das conclusões obtidas com o estudo. 


\section{Artefatos, Organizações Sem fins LuCrativos e a Abor- DAGEM CONTINGENCIAL}

Para a International Federation of Accountants (2008), a contabilidade gerencial é parceira na tomada de decisão, desenvolvendo sistemas de planejamento e gestão de desempenho, além de conhecimento a partir de relatórios e controles financeiros para auxílio na formulação e implementação da estratégia organizacional. A partir deste conceito é possível inferir alguns pontos importantes sobre a contabilidade gerencial. Em primeiro lugar, ela existe para auxiliar os gestores, seja com conhecimento ou com a criação de artefatos, o que corrobora a importância do gestor e do contexto levantada anteriormente. Outro ponto diz respeito ao fato de o objeto ser financeiro. O que é objeto ou não da contabilidade é questionado por críticos da contabilidade, dando origem, entre outros, a concepções como a de contabilidade social e contabilidade ambiental (MOOK, 2010). Embora estas concepções não tradicionais ainda sejam periféricas na teoria contábil, já há autores buscando aplicar tais conceitos à contabilidade gerencial de empresas, principalmente a contabilidade gerencial ambiental (MATHEWS, 2016).

Consideram-se artefatos de contabilidade gerencial neste trabalho, aquelas técnicas ou métodos que tratem de informações que auxiliem os gestores na consecução dos objetivos organizacionais (GODOY; RAUPP, 2017). Para analisar quais artefatos de contabilidade gerencial são utilizados pela organização objeto de estudo, foi levantada uma lista a partir dos trabalhos de Chenhall e Langfield-Smith (1998), Burriit et al. (2002), Soutes (2006), Mook (2010), Gabionetta (2011), Arruda (2012), Papaspyropoulos et al (2012), Mclellan e Moustafa (2013), e Pavlatos e Kostakis (2015). Em uma revisão de trabalhos sobre contabilidade gerencial no Brasil, Nascimento et al. (2010) verificaram que o uso destes artefatos não está unicamente relacionado à questão de desempenho, mas pode ser motivada por diversos fatores como o tamanho e a centralização. Para melhor compreender estas questões é necessário primeiro compreender o os atores relacionados ao seu uso, sejam elas as organizações sem fins lucrativos.

A definição de organizações sem fins lucrativos adotada neste trabalho é a de Salamon e Anheier (1998), na qual estas organizações 
compartilham de cinco características principais: institucionalização, socialmente aceitas como não fazendo parte do governo, não distribuição do lucro, autogeridas, atividade voluntária. A primeira década dos anos 2000 apresentou um acelerado crescimento na produção de trabalhos sobre estas organizações (VIEIRA, 2010), sendo que um importante exemplar foi o mapeamento do terceiro setor brasileiro em 2002, 2005 e 2010, resultante da parceria entre a Associação Brasileira de Organizações Não Governamentais (ABONG), o Grupo de Institutos, Fundações e Empresas (GIFE) e o Instituto Brasileiro de Geografia e Estatística (IBGE, 2012). Este trabalho contribuiu com os estudos da sociedade civil ao relevar a dimensão da importância destas organizações no Brasil, bem como institucionalizar o conceito operacional de Fasfil. Segundo este estudo, Fasfil relaciona Fundações e Associações Sem Fins Lucrativos, com critérios fundamentados no trabalho de Salamon e Anheier (1998), e incluindo no caso Brasileiro as seguintes formas jurídicas: Associações, Fundações e Organizações Religiosas.

Associações são constituídas, segundo o artigo 54 do Código Civil Brasileiro, "pela união de pessoas que se organizem para fins não econômicos" (BRASIL, 2002). Associações são, segundo Putnam (2002), formas de expressão da sociedade civil que incutem em seus membros valores democráticos, e, consequentemente, leva à estabilidade política. Se estes benefícios democráticos estão ligados ou não à participação dos membros e se realmente levam à estabilidade política, no entanto, é algo ainda amplamente debatido (ELSTUB, 2010). As fundações, por outro lado, são a expressão organizacional da filantropia por excelência (HARROW, 2010), por surgirem não de decisão social ou comunitária, mas sim do ímpeto filantrópico de um indivíduo ou instituição, com vistas a melhorar a sociedade segundo a sua visão. Quanto às organizações religiosas, estas são de livre formação e estruturação "sendo vedado ao poder público negar-lhes reconhecimento ou registro dos atos constitutivos e necessários ao seu funcionamento" (BRASIL, 2003). Apesar de a Igreja católica ser a representante mais expressiva destas organizações e ter papel quase hegemônico na sociedade civil brasileira (LANDIM, 2002), nas últimas décadas, a dinâmica entre organizações religiosas e demais organizações 
da sociedade civil tem mudado, representando um aumento da pluralidade religiosa do país (BURITY, 2007).

Apesar de as organizações sociais poderem ser enquadradas no conceito de Salamon e Anheier (1998), elas excluem parcelas importantes, como organizações religiosas, mutualistas, entre outras. Outra qualificação importante é a de Organizações da Sociedade Civil de Interesse Público (OSCIP), voltada para organizações sem fins lucrativos que trabalhem na provisão de serviços públicos, mas exclui, entre outras, as organizações sociais, cooperativas, organizações religiosas e entidades de benefício mútuo (BRASIL, 1999). Estas distinções estão fortemente ligadas às parcerias que o Estado procura estabelecer para a provisão de serviços, cuja relação teria sido ampliada pela Lei Federal no 13.019, (BRASIL, 2014), a qual ainda não entrou em vigor (BRASIL, 2015). Considerando que parte do objeto deste estudo - organizações sem fins lucrativos - e a adaptação do conceito à realidade brasileira, para este trabalho foi adotado o conceito operacional de Fasfil, fundações, associações e organizações religiosas, o qual considera organizações que cumpram os critérios definidos por Salamon e Anheier (1998).

A abordagem contingencial aplicada às organizações sem fins lucrativos apresenta usos não relacionados à questão de desempenho, como organizações que, a partir do entendimento da relação entre tamanho e estrutura organizacional, prefiram se manter pequenas para preservar uma estrutura não hierárquica em consonância com seus valores (BRADSHAW, 2009). Para identificar características contingenciais relacionadas ao uso de artefatos de contabilidade gerencial, foram adotadas as categorias de Chenhall (2003), exceto a variável cultura nacional ou cultura local. As outras variáveis são estrutura, ambiente, estratégia, tecnologia e tamanho organizacional, a partir das quais foram definidos índices para cada variável, com base na literatura.

Chenhall (2003, p. 144) descreve estrutura como sendo a definição formal de papéis específicos para os membros da organização, ou tarefas para grupos. Para operacionalizar este conceito, Espejo (2008) justifica que o grau de centralização é um bom construto para este fim, tendo em vista sua aceitação pela comunidade acadêmica. Lawrence e Lorsh (1973) tratam descentralização em termos de dis- 
tribuição da influência. Entretanto, a influência pode ser centralizada não somente em uma pessoa, mas em uma entidade. Por exemplo, uma cooperativa que dependa da assembleia geral para qualquer tomada de decisão acerca de investimento pode ser considerada centralizada, pois não delega qualquer poder para grupos ou pessoas individualmente, o que torna a organização menos orgânica.

Desta forma, adaptando o construto utilizado por Espejo (2008), foram considerados como índices para mensurar a centralização o número de entidades (indivíduos ou grupos) que podem tomar decisões acerca de contratações e demissões, criação de novos produtos e orçamento. Desconsiderou-se, para este construto, a questão do investimento por entender que está compreendida dentro do escopo do orçamento, bem como a questão de decisão de preços, pois nem todas as organizações sem fins lucrativos cobram seus serviços nestes termos.

Chenhall (2003) aponta que existem diversas abordagens para a avaliação do ambiente, e que elementos do ambiente podem gerar pressão ou prover oportunidades. Diversos trabalhos tratam o ambiente a partir da variável "incerteza", enquanto outros avaliam outras variáveis (ESPEJO, 2008). No entanto, estes trabalhos geralmente tratam o ambiente como sendo o mercado, e os elementos citados por Chenhall (2003) incluem concorrentes, clientes e fornecedores. Partindo-se da compreensão de que o ambiente externo a uma organização é complexo, serão utilizadas duas abordagens para tentar abranger esta complexidade, uma relativa ao ambiente direto da organização, e outra ao indireto. O ambiente indireto, também referido como macro ambiente, ambiente geral ou ambiente maior, constitui-se de influências que não são dirigidas àquela organização específica, mas são contingências que afetam conjuntos de organizações. Já o ambiente direto, operacional ou específico, refere-se a influências diretamente voltadas à organização em estudo (ANDRADE; AMBONI, 2010).

Para abordar o ambiente direto foi feito um mapeamento dos stakeholders que fazem parte do processo da organização, bem como suas relações de poder, partindo-se do entendimento que, ao possuírem relações de poder com a organização em estudo, sua influência pode ser caracterizada como direta. Stakeholders podem ser entendi- 
dos como grupos ou indivíduos que podem afetar ou são afetados pelo alcance dos objetivos organizacionais (FREEMAN, 1984). Jordan (2005) identifica que para as estas organizações existem, no mínimo seis stakeholders: governo; doadores; movimentos sociais e outras ONGs; beneficiários; força de trabalho; e setor privado. Para abordar o ambiente indireto, será utilizada a abordagem institucional. Esta abordagem propõe que uma organização tenderá a se adequar às normas consideradas socialmente legítimas (MILLER-MILLESEN, 2003). Este processo, segundo Dimaggio e Powell (1983), ocorre de forma coercitiva, a partir do exercício de poder por parte de uma entidade, de forma mimética, quando uma organização adota práticas de organizações similares devido às incertezas enfrentadas, ou de forma normativa, que é quando a organização adota determinadas práticas tidas por certa classe profissional como legítimas, normalmente por haver um destes profissionais no quadro da organização.

Ao analisar revisões sobre o tema estratégia (ANTÓNIO, 2003; MINTZBERG, AHLSTRAND, LAMPEL, 2009; ANDRADE, AMBONI, 2010) é possível discernir que a estratégia organizacional está relacionada à escolha de meios e fins de uma organização. Vários aspectos são apresentados por diferentes perspectivas como sendo mais ou menos influentes em relação à estratégia, mas a perspectiva comum é o que fazer e como chegar lá.

Como variável contingencial, a estratégia é tradicionalmente abordada do ponto de vista empresarial, com definições como a de Porter (1980) de estratégia de liderança em custo ou diferenciação. Moore (2000) explica que as empresas buscam aumentar o valor aos acionistas, e o fazem com a comercialização de bens ou serviços. Já as organizações sem fins lucrativos e governamentais têm objetivos sociais, difíceis de mensurar, e o seu desempenho no alcance de tais objetivos não garante a percepção de recursos para a operação da organização, como acontece nas empresas. No entanto, para conseguir aproximar a estratégia de organizações sem fins lucrativos e públicas, o autor faz um recorte da sociedade civil, considerando apenas organizações que recebem uma relevante parte de seus recursos de doações e geram valor social para além das do valor aos consumidores, de forma a conseguir relacionar receita e produção. 
Em se tratando de estratégia voltada a organizações sem fins lucrativos, Stone et al. (1999) trazem uma revisão da literatura abordando a estratégia em três partes: formulação, conteúdo e implementação. No entanto, a estratégia como processo não é o escopo deste trabalho. Desta forma, a questão será abordada a partir da concepção de estratégia como perspectiva, ou seja, como a forma com que uma organização realizar as coisas (MINTZBERG, AHLSTRAND, LAMPEL, 2009).

Para tecnologia foi adotado o conceito de Chenhall (2003) em que a tecnologia, para a organização, representa como ocorrem os processos organizacionais. O autor deriva deste conceito duas dimensões da tecnologia: complexidade e incerteza nas tarefas. Para operacionalizar a complexidade, buscou-se classificar os produtos em padronizados ou personalizados. Por padronizados, compreendemse aqueles produtos criados de forma massificada, todos iguais. Já personalização, ou customização pura, é quando o produto é produzido de maneira ad hoc (BLECKER et al., 2003 apud PELEGRINI, 2005). Pelegrini (2005) aponta a relação direta entre complexidade dos processos e nível de personalização.

Perrow (1970 apud CHENHALL, 2003) explica que a incerteza de uma tarefa está inversamente relacionada à possibilidade de determinada tarefa ser analisada e controlada. Desta forma, tarefas mais incertas têm resultados subjetivos, e serão combinadas para criar processos com resultados também subjetivos. Sendo o resultado de um processo o produto, produto cuja avaliação seja primariamente subjetiva terá um processo primariamente incerto. No entanto, produtos semelhantes em contextos diferentes podem ter avaliações diferentes. Uma cadeira produzida por uma associação de artesãos é uma unidade objetivamente analisável, enquanto se produzida por um grupo artístico é uma obra de arte subjetiva.

Ainda assim, não há necessariamente uma relação direta entre padronização e incerteza, pois uma palestra padronizada de prevenção ao HIV será avaliada subjetivamente, enquanto uma cirurgia ad hoc tende a ser avaliada em termos objetivos. Desta forma, os índices "incerteza das tarefas" e "complexidade" são avaliados qualitativamente a partir do tipo de produto e seu contexto, e classificadas em complexo (ad hoc) ou simples (padronizado) e incerto (subjetivo) ou rotineiro (objetivo). 
Chenhall (2003) explica que o tamanho de uma organização pode ser medido de diversas formas, como receita bruta, total de ativos, número de clientes, total de funcionários, etc. Este autor alerta, no entanto, que diferentes medidas podem ser mais adequadas a diferentes estudos. Para o presente estudo, levando-se em consideração que os artefatos de contabilidade gerencial estão ligados à gestão de recursos tradicionalmente financeiros, o critério de seleção do caso de estudo foi o tamanho da organização em termos de receita bruta.

Isto posto, não se pode ignorar a influência de outros fatores, de forma que serão considerados dois indicadores para tamanho: Receita bruta e número de colaboradores não eventuais, contratados e voluntários (ABDEL-KADER, 2014). No entanto, não foi encontrada uma referência adequada para classificar estas instituições, visto que a classificação do IBGE (2012) considera apenas colaboradores assalariados, não abrangendo a importância dos trabalhadores voluntários, também em vista da dificuldade de serem abordados em um estudo de tal magnitude. Por este motivo, a organização estudada não foi categorizada por número de colaboradores não eventuais e nem por receita bruta. $\mathrm{O}$ indício utilizado para apontar a existência ou não de influência do tamanho organizacional no uso dos artefatos de contabilidade gerencial foi a variação do tamanho organizacional, conforme sugere Chenhall (2003), a partir da variação destes dois indicadores, número de colaboradores não eventuais e receita bruta.

\section{Procedimentos Metodológicos}

Diante de uma demanda por explorar a existência de laços de causalidade entre as características contingenciais das organizações sem fins lucrativos e o uso de artefatos de contabilidade gerencial. Desta forma, é possível enquadrar o objetivo desta pesquisa como exploratório, pois objetiva uma maior familiaridade e compreensão do tema (GIL, 2002).

Parte-se do pressuposto que os artefatos, tendo sido eminentemente criados para empresas, não sejam adequados para organizações com características diferenciadas, como é o caso da organização a ser estudada. Para verificar este pressuposto, optou-se por um estudo de caso. Esta escolha se justifica pelo alinhamento com os 
objetivos exploratórios da pesquisa, visto que um estudo de caso consiste em um estudo aprofundado de um objeto, de forma a gerar um conhecimento amplo e detalhado sobre o mesmo (GIL, 2002).

Para empreender um estudo de caso é importante levar em conta os cinco pontos fundamentais destacados por Yin (2015): as questões em estudo; suas proposições, se houver; sua(s) unidade(s) de análise; a lógica que une os dados às proposições; e os critérios para interpretar as constatações. As questões em estudo foram apresentadas na introdução, sob a forma de tema, problema e objetivo, e a proposição desta pesquisa é o pressuposto acima comentado. Considerando o objetivo deste trabalho, foi definida como unidade de análise o artefato de contabilidade gerencial, entendido como técnica ou método que trate de informações que auxiliem os gestores na consecução dos objetivos organizacionais. O ambiente no qual este uso foi investigado é o de uma organização sem fins lucrativos sendo necessário portanto, compreender e mapear as características da organização.

Conforme discutido na introdução, o objeto desta pesquisa é o uso de artefatos de contabilidade gerencial por organizações sem fins lucrativos. Assim sendo, foi selecionada uma organização que se encaixa neste perfil, para qual assume-se que adote e utilize algum tipo de artefato contábil. Esta presunção do uso, parte do entendimento apresentado por Chenhall (2003), de que um maior tamanho organizacional está associado a uma maior especialização, formalização, e controles sofisticados. O caso objeto de estudo foi o Instituto Vilson Groh (IVG), uma associação de entidades sociais. Dentre as organizações existentes em Florianópolis, procurou-se dar prioridade ao conjunto de organizações com maior tamanho, sendo este medido em receita bruta anual, em decorrência do objeto desta pesquisa estar relacionado à gestão de recursos. Quanto mais recursos, espera-se que maior seja o uso de artefatos. Além disso, espera-se que organizações de maior tamanho apresentem pessoas especializadas no uso de controles contábeis, e que os usem de forma sofisticada, permitindo a análise de variações, adaptações ou congruências com os modelos tradicionais. Outro critério para a seleção, visando abranger a variedade de organizações classificadas como sem fins lucrativos, é o papel estratégico desempenhado pelas organizações na sociedade (GODOY; RAUPP, 2017). 
A coleta de dados se deu em três etapas. A primeira etapa foi o contato inicial. Com o apoio de um intermediário ligado à organização, foi marcada uma conversa com um representante para apresentação da pesquisa. A segunda etapa consistiu no levantamento de dados secundários. Foram pesquisadas informações sobre a organizações a partir de seus próprios canais de comunicação (sites, blogs, mídias sociais etc.), trabalhos acadêmicos realizados sobre ela, e textos jornalísticos. Após o levantamento de dados secundários, poderiam ser necessárias uma ou mais visitas às instalações da organização, em uma etapa de observação, para melhor compreender seu funcionamento.

A etapa final da coleta de dados foi a de entrevista, na qual foram validadas as informações previamente coletadas, além de levantadas respostas aos questionamentos orientados pelo guia de entrevista desenvolvido, para compreender o uso dos artefatos pelo entrevistado, o motivo de sua adoção e sua finalidade. O entrevistado é formado em economia e administração pública, além de mestre em administração, e trabalha no Instituto desde sua fundação em 2010. Sua experiência profissional está intimamente ligada à Instituição, pois seu primeiro emprego formal foi no Centro Cultural Escrava Anastácia, que hoje faz parte da rede do IVG. Seu vínculo empregatício, tal como dos outros funcionários, é contrato de trabalho por tempo indeterminado. É responsável pela gestão dos recursos da instituição, bem como presta assessoria administrativa financeira às instituições da rede.

A partir da construção teórica obteve-se uma lista com 92 artefatos. Esta não pretendeu ser uma lista exaustiva, mas foi usada para definir algumas categorias de artefatos existentes para formular as questões de entrevista, de forma a permitir que outros artefatos fossem descritos.

A técnica de análise dos dados foi a análise de conteúdo, com abordagem qualitativa, cujo foco é a inferência fundada na presença de índices relativos às variáveis analisadas, e não sua frequência (BARDIN, 1979). Segundo Bardin (1979) a análise de conteúdo designa um conjunto de técnicas de análise das comunicações visando obter, por procedimentos sistemáticos e objetivos da descrição do conteúdo das mensagens, indicadores (quantitativos ou não) que permitam a 
inferência de conhecimentos relativos às condições de produção/recepção (variáveis inferidas) destas mensagens. Desta forma, o primeiro passo da análise foi identificar a existência dos artefatos da lista no conteúdo da entrevista, ou identificar neste mesmo conteúdo novos artefatos, desde que estes sejam, conforme explicado na revisão da literatura, "técnicas ou métodos que tratem de informações que auxiliem os gestores na consecução dos objetivos organizacionais". A partir da identificação do uso de artefatos de contabilidade gerencial no conteúdo da entrevista, seguiu-se à relação entre o uso deste artefato e características contingenciais da organização.

\section{Resultados da Pesquisa Empírica}

\subsection{Instituto Pe. Vilson Groh}

O Instituto Pe. Vilson Groh (IVG) é uma associação privada formada por organizações com fins assistenciais, fomentando a cooperação em rede destas organizações. O primeiro contato com a instituição baseou-se na expectativa de avaliar um caso do papel estratégico Coordenação. No entanto, ao compreender a atuação em rede fomentada e suportada pelo IVG, percebeu-se que se tratava de uma organização que desempenha papéis estratégicos de Formação de Capital, Produção e Ação Política.

A história do Instituto se confunde com a de seus membros, visto que este é a institucionalização da atuação em rede das organizações que dele fazem parte. Para além disso, ele é a institucionalização do próprio sacerdote que lhe dá nome, seja como articulador da rede ou como apoiador do trabalho destas organizações. O IVG foi fundado em 2010, pelo Centro Cultural Escrava Anastácia (CCEA), Centro Social Elisabeth Sarkamp (CSES), Centro de Educação e Evangelização Popular (CEDEP), Associação de Amigos da Casa da Criança e do Adolescente do Morro do Mocotó (ACAM), Centro Educacional Marista São José (CEMSJ) e Lúcia Mayvorne (CEMLM). Desde 2013, a entidade buscou certificações públicas como Utilidade pública Municipal e Estadual, bem como seu registro no Conselho Municipal de Assistência Social de Florianópolis. Também em 2013, o Instituto teve o ingresso do seu primeiro associado não fundador, a Associação João Paulo II, do município de Palhoça. 


\subsection{Características contingenciais}

O caso do IVG demanda a construção de um organograma não tradicional, conforme é possível perceber na Figura 1.

Figura 1 - Organograma IVG

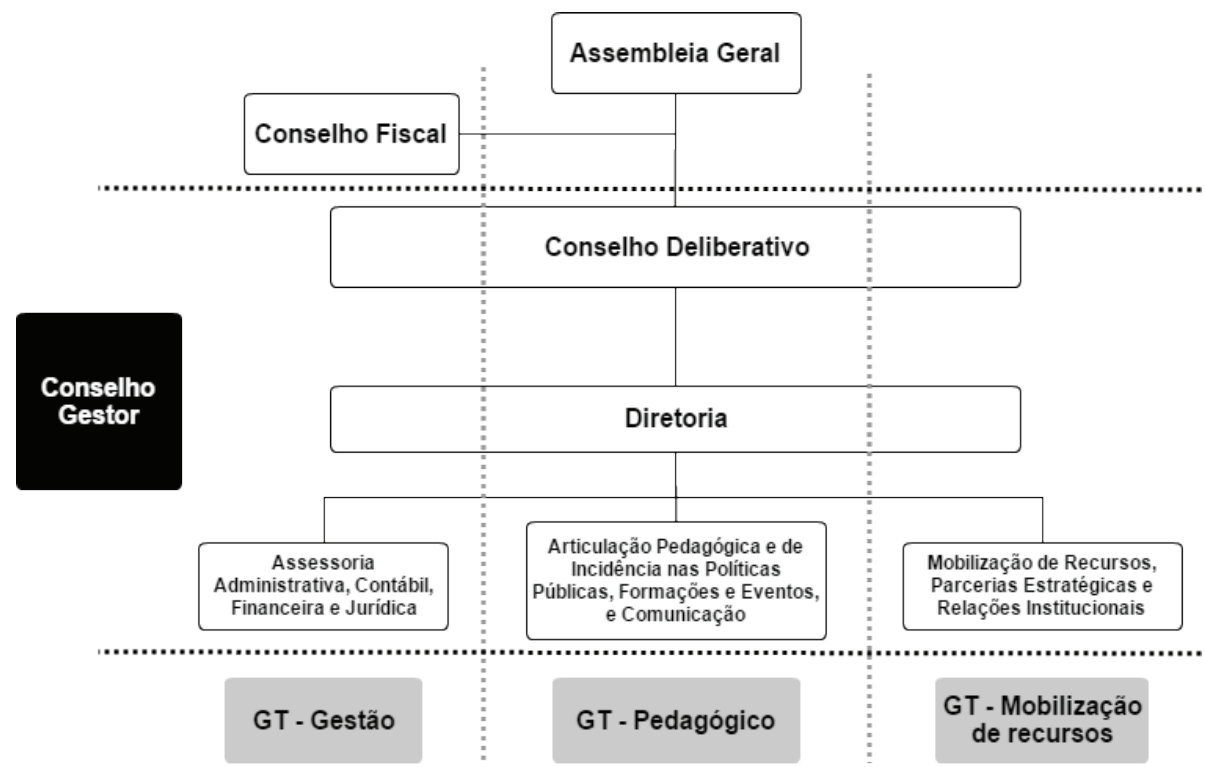

Fonte: Elaboração própria (2017).

É possível observar, por meio da Figura 1, funções formalmente definidas. As linhas verticais em cinza representam a constituição dos grupos de trabalho (GTs). Estes GTs são responsáveis pela implementação das ações articuladas pela rede de associadas. Em relação ao o conselho gestor, conforme explica Schefer (2014), mensalmente, os representantes das organizações, que fazem parte do conselho deliberativo, se reúnem com a equipe de trabalho do IVG e membros da diretoria (normalmente o presidente) e discutem ações que são desenvolvidas em conjunto pelas organizações. A este núcleo foi dado o nome de conselho gestor.

Tais características fundamentam organograma como não tradicional pois, embora o poder de aprovar orçamentos, criar novos produtos, contratar e despedir pessoas seja formalmente prerrogativa da diretoria, quem normalmente delibera e decide sobre estes assuntos 
é o conselho gestor, salvo em caso de orçamentos anuais, os quais são aprovados em assembleia. Assim sendo, é possível compreender que a estrutura do IVG seja centralizada no conselho gestor.

No tocante ao ambiente, como segue apresentado por meio do fluxograma na Figura 2, é possível identificar os principais stakeholders relacionados ao Instituto, sendo que a relação mais simples do Instituto com stakeholders é a deste com a comunidade de Empada, na Guiné Bissau, que recebe do IVG, e de doadores privados, suporte educacional a seis de suas escolas.

Figura 2 - Fluxograma IVG

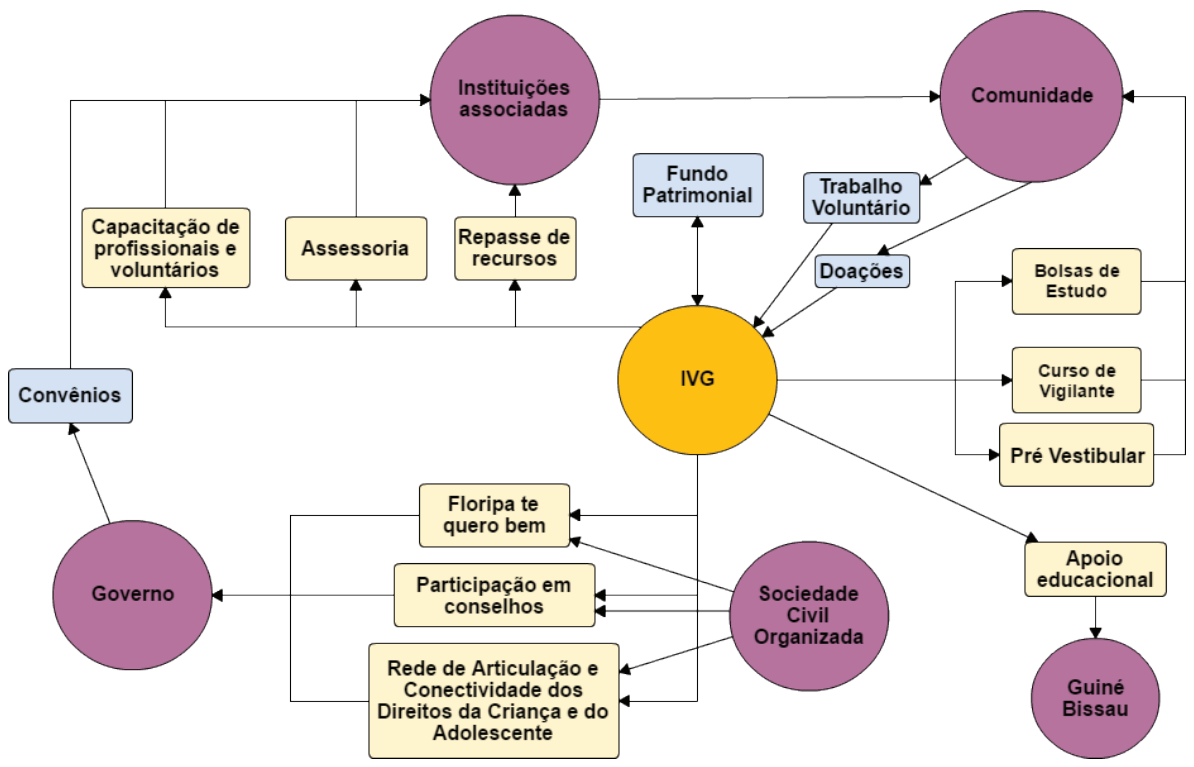

Fonte: Elaboração própria (2017).

A comunidade de Empada não apresenta praticamente nenhum poder sobre o Instituto, por ser uma comunidade afastada, tendo pouco impacto normativo social, não tendo poder utilitário nem coercitivo. O Instituto exerce poder utilitário sobre ela, na medida em que provê financiamento para serviços voltados a esta comunidade, sendo ainda uma relação pouco significativa em termos de poder.

Uma relação similar é a do IVG diretamente com a comunidade onde está inserido, embora o poder normativo desta seja significa- 
tivamente maior, visto que é onde o IVG e suas associadas estão inseridos e a quem se destina a maior parte de seus serviços. Neste caso, apesar do poder utilitário do Instituto também ser maior, o poder normativo social da comunidade o supera, além de ser da comunidade que advém boa parte dos recursos do IVG, como trabalho voluntário e doações, tornando uma relação de poder onde a sociedade figura como mais poderosa.

Outra relação de poder em que Instituto é a parte menos poderosa é a relação com as instituições a ele associadas. Afinal, atendê-las é o objetivo do IVG, dando-as poder normativo social, e elas são ao mesmo tempo proprietárias do Instituto, tendo ainda mais poder normativo e utilitário. Ainda assim, o Instituto possui certo poder utilitário sobre elas, pelos serviços que presta e pelos repasses de recursos.

A relação do Instituto com as organizações da sociedade civil é de parceria, de forma que é difícil identificar relações de poder entre elas. Estas parcerias são em projetos ou ações específicas, como o movimento Floripa te Quero Bem, no qual o IVG, em parceria com estas organizações, faz demandas políticas ao governo, como a aprovação de uma emenda à lei orgânica do município de Florianópolis relativa à criação de planos de metas para a gestão municipal.

A relação com o governo é recíproca, pois o IVG, diretamente ou por meio de suas parcerias, realiza pressão política sobre o governo, principalmente municipal, enquanto este, apesar de não financiar o Instituto diretamente, é importante financiador de suas associadas, possuindo poder utilitário sobre o Instituto a partir do poder utilitário que possui sobre suas associadas. Compreendidos estes principais stakeholders, é possível analisar o ambiente indireto.

No ambiente indireto, a principal fonte de isomorfismo que se pôde verificar foi normativa, em especial pela participação de empresários na diretoria e em outras ações mais pontuais como afirma o Entrevistado: “O empresário traz muito isso, eles estão muito acostumadas com isso, como o Qlick View por exemplo [...], o nosso diretor faz um curso internacional no GIFE, MBA em governança, então eu acho que isso teve um crescimento de demanda nosso".

Estas ações não se restringem aos diretores, todos os funcionários participam de cursos e aperfeiçoamentos, estando em constante 
contato com as melhores práticas de gestão, o que indica uma clara influência normativa. Isto posto, pode-se avançar para entender os papéis estratégicos desempenhados pelo IVG.

Conforme apresentadas na Figura 2, as atividades desempenhadas regularmente pelo IVG em relação à comunidade, sejam elas o curso pré-vestibular, o curso de vigilantes e as bolsas de estudos, visam aumentar a capacidade dos atendidos de gerar benefício futuro, caracterizando o papel de formação de capital do Instituto. O mesmo pode ser dito em relação às formações e capacitações destinadas às instituições associadas ao IVG.

Ainda em relação a suas associadas, o IVG tem potencial para desempenhar um forte papel de coordenação, por realizar assessorias e repasses de recursos. No entanto, conforme a relação de poder apresentada acima, o IVG não exige contrapartidas específicas de suas associadas, caracterizando estas atividades como serviços efêmeros, o que evidencia o desempenho do papel estratégico produção. Este papel estratégico é bastante importante até mesmo em ações pontuais da organização, como explica o Entrevistado: “A primeira questão é aquilo que eu te falei que o nosso foco é sempre atividade-fim. Morador de rua? Eu não vou ficar aqui fazendo uma planilha, se apertar eu vou lá falar com ele".

Além disso, ainda é possível identificar o papel de ação política da organização, nas atividades em parceria com as organizações da sociedade civil, como a participação no Floripa te Quero Bem, que gera demandas ao poder público municipal. A seguir serão analisadas estas atividades do ponto de vista tecnológico.

Em relação à tecnologia, foi possível identificar as atividades à comunidade como padronizadas, visto que mudam pouco a cada ano. Todas as outras atividades são mais complexas, tendo caráter ad hoc, pois cada reunião de conselho, cada assessoria, cada repasse de verbas depende de uma demanda muito específica. A exceção é o Fundo Patrimonial, cuja manutenção é regular, incluindo uma análise do risco financeiro e da rentabilidade padronizada.

Quanto à previsibilidade, o fundo patrimonial gera resultados objetivos: dinheiro. Da mesma forma, é possível medir de forma objetiva as atividades à comunidade, como o pré-vestibular pelo índice de aprovação e o curso de vigilantes pelo índice de contratação. Já 
as capacitações e assessorias às instituições associadas não são tão facilmente avaliadas, possuindo caráter mais subjetivo, da mesma forma que a atuação do Instituto em parceria com as organizações da sociedade civil.

Uma atividade cuja análise não é tão clara são os repasses às instituições associadas, pois o valor repassado é objetivamente analisável. No entanto, não é possível estabelecer uma análise objetiva de "quanto mais, melhor", pois muitos destes repasses são emergenciais, de forma que o número apresentado não é suficiente para avaliar o desempenho da atividade. Já no apoio à Guiné Bissau, não só o valor repassado é objetivamente analisável, como também o número de crianças atendidas com cada tipo de atendimento. Compreendendo as atividades do IVG é possível melhor compreender sua estrutura.

Para a características tamanho, em 2015 o Instituto obteve um faturamento total de $\mathrm{R} \$ 876.423,80$, além de $\mathrm{R} \$ 139.960,00$ contabilizados como trabalho voluntário. Já no critério colaboradores, o IVG conta com três funcionários CLT, além de dois diretores que frequentam semanalmente a instituição. Assim sendo, poder-se-ão analisar os artefatos adotados pelo IVG.

\subsection{Artefatos de contabilidade gerencial}

Foram identificados 13 artefatos utilizados pelo IVG. O primeiro artefato identificado foi o fluxo de caixa. No caso do IVG, o fluxo de caixa é realizado com o uso de um software, e foi identificado que a adoção deste controle se deu pelo seu uso por parte das instituições associadas. Para o Entrevistado, "antes, a gente fazia tudo no Excel. No Centro Cultural a gente até fazia e a contabilidade refazia". As instituições associadas, conforme visto anteriormente, apresentam um poder normativo social em relação ao IVG, e elas próprias decidiram que o IVG deveria ser gerido por pessoas que já faziam parte de alguma das organizações fundadoras, neste caso o Centro Cultural Escrava Anastácia.

Já o orçamento por fluxo de caixa realizado pelo IVG teve como causas de seu uso a estruturação por projetos (alta complexidade) que é demandada de suas associadas (ambiente direto). Foi identificada também a influência normativa na adoção do software, no caso por indicação da empresa de contabilidade contratada pelo Instituto. 
Relacionado a estes artefatos, foi identificado o uso da análise da diferença entre o orçado e realizado, que também apresentou influência das instituições associadas (poder normativo) e de boas práticas de gestão financeira (ambiente indireto normativo). Além destes dois motivos, identificou-se a influência utilitária da comunidade que financia o trabalho do IVG por meio de doações e a estratégia de formação de capital, conforme fala do Entrevistado: “Mas eu acho que isso é uma coisa quase um consenso, que era importante a gente se organizar desse jeito, até porque sempre se teve a ideia de disseminar esse conhecimento com as ONGs".

Ainda em relação ao controle de recursos, foram identificados dois artefatos adotados por questões legais, o que identifica influência coercitiva do ambiente indireto. O primeiro destes artefatos é o registro de hora voluntária e o segundo é o registro das doações, que além de ter sido adotado pelas questões anteriormente citadas, está relacionado ao papel estratégico produção, visto que prestam assessoria para suas associadas neste sentindo.

No processo de planejamento em nível estratégico, foi possível identificar um conjunto de artefatos. O primeiro é a análise SWOT, adotada, segundo o Entrevistado, por influência normativa de membros da diretoria que gerenciam empresas: "A análise SWOT, a tendência é que ela fique e eu acho que o 5W2H também. O empresário traz muito isso, eles estão muito acostumados com isso".

O IVG também utiliza como suporte a seu planejamento estratégico a análise de seus stakeholders com o auxílio do Eco-mapa. Toda organização da sociedade civil vive em um ecossistema, uma rede dinâmica de relações que influenciam e mesmo determinam a sua maneira de ser e atuar. Observar e estudar as interações da organização com seus múltiplos interessados para orientar as decisões é um caminho para nutrir sua vitalidade e senso de propósito (INSTITUTO FONTE, 2006). O uso desta ferramenta está novamente associado a uma influência normativa do ambiente indireto, oriunda dos cursos realizados pelos gestores do IVG. No entanto, enquanto estas ferramentas facilitam a organização das informações para a tomada de decisão estratégica, esta é realizada por meio de reuniões constantes entre os membros do conselho gestor, o qual inclui representantes das instituições associadas. 
Pelo fato de as decisões serem concentradas neste conselho, o que indica uma estrutura centralizada, dois artefatos foram adotados. O primeiro é o registro das reuniões, servindo não só como apoio para a execução do planejamento, mas também como forma de avaliar o desempenho do Instituto, dada subjetividade de suas atividades, que tornam avaliações mais qualitativas necessárias. $\mathrm{O}$ segundo artefato adotado em decorrência desta centralização da estrutura organizacional do IVG é o relatório de gestão. No caso do IVG, seu uso também se deve à prestação de serviços a suas associadas, ou seja, ao papel estratégico produção, pois o Instituto desenvolveu ferramentas de prestação de contas além de suas próprias exigências, mas alinhadas com as exigências de suas associadas. Não se pode ignorar, no entanto, a presença novamente do ambiente indireto e de sua influência normativa oriunda das demandas sociais de legitimidade e prestação de contas.

Relacionado ao relatório de gestão estão os artefatos utilizados para avaliar o desempenho da organização. O primeiro é a pesquisa de satisfação, utilizada em decorrência do relatório e da centralização das decisões no conselho gestor. Outro artefato também relacionado à centralidade da estrutura do IVG é a avaliação de risco financeiro, avaliada pelo conselho gestor, em relação ao fundo patrimonial desenvolvido pelo IVG. Outros motivos para esta avaliação são o grau de aversão ao risco, identificado como alto, e a baixa incerteza do fundo, pois, apesar de haver risco envolvido, seus resultados podem ser objetivamente analisados por índices de rentabilidade.

O último artefato identificado é ainda relacionado à mensuração do desempenho, neste caso dos atendimentos que o IVG presta a suas associadas, cuja avaliação é subjetiva. Trata-se de um software de Customer Relationship Management (CRM). Ragins e Greco (2003, p. 25) explicam CRM nos seguintes termos: "os objetivos dos processos de CRM são moldar a percepção que os clientes têm da organização e seus produtos com a identificação destes clientes, criação de conhecimento sobre estes clientes e construção de relacionamentos com clientes de forma comprometida". O IVG, no entanto, usa o software como forma de registrar as atividades realizadas, conforme explica o Entrevistado: 
É V-Tiger o nome do sistema, e até uma função nossa, de quantos atendimentos eu realizei, eu estou aqui contigo, é um atendimento, fui ali conversar com o cara, é um outro atendimento, eu fiz meus lançamentos financeiros, é um atendimento, eu atendi uma demanda da ONG, é um atendimento.

Este uso do sofwtare está relacionado à natureza ad hoc dos serviços realizados pelo Instituto, bem como ao grau de incerteza devido à subjetividade do seu desempenho. A adoção deste software em específico foi uma influência do ambiente indireto, no caso da empresa de contabilidade, de caráter normativo, e também está relacionada ao papel estratégico de coordenação: “O que é mais importante para a gente é mostrar se, de fato, a gente está atendendo bem uma criança. Por isso a gente precisa ver quantas vezes a gente atendeu ela, quantas vezes ela foi no psicólogo, quantas vezes o educador atendeu ela, para a gente começar a ter o histórico dela, um registro" (Entrevistado).

Os resultados coadunam com Nascimento et al. (2010), que entendem que o uso dos artefatos pode ser motivada por diversos fatores como o tamanho e a centralização, e não unicamente à questão de desempenho. Assim sendo, foi possível resumir os artefatos identificados, bem como os motivos para seu uso, na Figura 3.

\section{CONSIDERAÇões FinAis, LiMITAÇões E RECOMENDAÇõeS PARA ESTUDOS FUTUROS}

A indagação motivadora do estudo questionou como os artefatos de contabilidade gerencial são adotados e utilizados por uma organização sem fins lucrativos. Tal pergunta de pesquisa foi respondida por meio do objetivo que consistiu em analisar o uso de artefatos de contabilidade gerencial em uma organização sem fins lucrativos de Florianópolis, Santa Catarina, à luz de características contingenciais. Uma característica marcante do caso IVG, objeto empírico, é que este foi constituído para institucionalizar a atuação em rede que já vinha acontecendo entre algumas de suas associadas, o que leva a influência normativa destas organizações a terem destaque na adoção de artefatos de contabilidade gerencial do Instituto. 
Figura 3 - Artefatos e razões para o uso

\begin{tabular}{|l|l|}
\hline Artefatos & Motivos \\
\hline Fluxo de caixa & $\begin{array}{l}\text { Ambiente direto (instituições asso- } \\
\text { ciadas, normativo social) }\end{array}$ \\
\hline Orçamento de fluxo de caixa & $\begin{array}{l}\text { Tecnologia (complexidade ad hoc) } \\
\text { Ambiente direto (instituições asso- } \\
\text { ciadas, normativo social) } \\
\text { Ambiente indireto (normativo) }\end{array}$ \\
\hline $\begin{array}{l}\text { Análise da diferença entre orça- } \\
\text { do e realizado }\end{array}$ & $\begin{array}{l}\text { Ambiente indireto (normativo) } \\
\text { Ambiente direto (instituições asso- } \\
\text { ciadas, normativo) } \\
\text { Ambiente direto (comunidade, } \\
\text { utilitário) } \\
\text { Estratégia (formação de capital) }\end{array}$ \\
\hline Registro de hora-voluntária & Ambiente indireto (coercitivo) \\
\hline Registro de doações & $\begin{array}{l}\text { Estratégia (Produção) } \\
\text { Ambiente indireto (coercitivo) }\end{array}$ \\
\hline Análise SWOT & Ambiente indireto (normativo) \\
\hline Análise de stakeholders & Ambiente indireto (normativo) \\
\hline Registro de Reuniões & $\begin{array}{l}\text { Estrutura (centralização) } \\
\text { Tecnologia (incerteza, subjetivo) }\end{array}$ \\
\hline Relatório de gestão & $\begin{array}{l}\text { Estrutura (centralizada) } \\
\text { Ambiente Indireto (normativo) } \\
\text { Estratégia (produção) }\end{array}$ \\
\hline Pesquisa de satisfação & $\begin{array}{l}\text { Relatório de gestão } \\
\text { Estrutura (centralizado) }\end{array}$ \\
\hline Avaliação de risco financeiro & $\begin{array}{l}\text { Estrutura (Centralização) } \\
\text { Tecnologia (previsibilidade, objeti- } \\
\text { vo) }\end{array}$ \\
\hline Customer Management Relationship & $\begin{array}{l}\text { Complexidade (ad hoc) } \\
\text { Incerteza (subjetivo) } \\
\text { Estratégia (coordenação) } \\
\text { Ambiente indireto (normativo) }\end{array}$ \\
\hline
\end{tabular}

Fonte: Elaboração própria (2017).

Quanto aos achados, quatro artefatos tiveram sua adoção influenciada pela presença destas instituições associadas, inclusive aliada ao papel estratégico da organização de prestar serviços de 
assessoramento a suas associadas, de forma que lhe é demandada o domínio das técnicas de prestação de contas demandadas dessas associadas: "A gente tem um procedimento parecido, até porque teoricamente a gente presta assessoria para as ONGs também, então a gente tem que ter um entendimento da lei, e como funciona o andamento dessas ONGs, então a gente tenta fazer um alinhamento conceitual desse procedimento". (Entrevistado).

Neste caso é possível perceber a dissonância descrita por Eckerd e Moulton (2010), onde a organização adota artefatos por influência do ambiente, neste caso das associadas e, indiretamente, do governo, mas não os utiliza para a tomada de decisão. No entanto, a utilização destes artefatos não foi identificada como motivada pelos papéis estratégicos desempenhados, mas sim por forte influência isomórfica normativa, oriunda da experiência em gestão de empresas dos diretores, e da centralização da estrutura. É importante ressaltar que os artefatos considerados neste trabalho são aqueles que de fato são utilizados para a tomada de decisão. Assim sendo, no caso do IVG, a adoção de artefatos de contabilidade gerencial a partir de isomorfismo normativo é potencializado pela centralização da estrutura organizacional. Em relação aos artefatos é relevante destacar a adoção de uma análise de stakeholders por meio do Eco-mapa, ferramenta voltada especificamente para organizações sem fins lucrativos (INSTITUTO FONTE, 2016). Também cabe destacar a utilização de uma ferramenta de Customer Relationship Management, o V-Tiger, não para modificar a experiência dos usuários de seus serviços, como preconizam Ragins e Greco (2003), mas para mensurar seu desempenho face à complexidade da execução e subjetividade da avaliação de suas atividades. Outros artefatos utilizados também para este fim são o registro de reuniões e a pesquisa de satisfação. No caso IVG, é possível afirmar que suas atividades, de avaliação subjetiva, levaram ao uso de ferramentas de controle como medidas de desempenho.

O estudos adotou as categorias de Chenhall (2003), exceto a variável cultura nacional ou cultura local, para identificar características contingenciais relacionadas ao uso de artefatos de contabilidade gerencial. Embora haja trabalhos anteriores que tragam as informações sobre a cultura brasileira e local, os procedimentos metodológicos adotados no presente estudo não são suficientemente 
robustos, ou seja, limitados para identificar se o uso de determinado artefato se deve à cultura nacional, regional, organizacional ou a valores individuais.

Em termos de recomendações, na análise da relação entre características contingenciais e a adoção e uso dos artefatos, por se tratar de um estudo exploratório, culminou com a produção de conclusões acerca do caso estudado, as quais podem ser transformadas em questionamentos ou hipóteses para pesquisas futuras: atividades de avaliação subjetiva levam à adoção de artefatos de controle como medidas de desempenho; a adoção de artefatos de contabilidade gerencial por meio do isomorfismo normativo é potencializada pela centralização da estrutura organizacional; e o incentivo à capacitação dos colaboradores da organização potencializa a influência das comunidades de prática na adoção de artefatos pela organização. Outros estudos sobre as relações entre características contingenciais e os artefatos identificados neste caso, no entanto, poderão suscitar novos questionamentos, visto que esta análise não pretende ser exaustiva.

\section{REFERÊNCIAS}

ABDEL-KADER, B. W. M. Contingency theory, performance management and organisational effectiveness in the third sector: a theoretical framework. International Journal of Productivity and Performance Management Accounting Research, v. 63, n. 6, p. 680-703, 2014.

ANDRADE, R. O. B. de; AMBONI, N. Estratégias de gestão: processos e funções do administrador. Rio de Janeiro: Elsevier, 2010.

ANTÓNIO, N. S. Estratégia organizacional: do posicionamento ao movimento. Lisboa: Edições Sílabo, 2003.

ARRUDA, L. L. Ferramentas de contabilidade gerencial no terceiro setor: Um estudo comparativo entre as WWF Brasil e Itália. 2012. 144 f. Dissertação (Mestrado em Contabilidade) - Universidade Federal do Paraná, Curitiba, 2012.

BARDIN, L. Análise de conteúdo. Lisboa: Edições 70, 1979.

BÖHM, S. Positioning organizanional theory. In: BÖHM, S. (Ed.). Repositioning Organization theory: impossibilities and strategies. Basingstoke: Palgrave, 2006.

BRADSHAW, P. A contingency approach to nonprofit governance. Nonprofit Management and Leadership, v. 20, n. 1, p. 61-81, 2009.

BRASIL. Lei $\mathbf{n}^{0}$ 9.790, de 23 de março de 1999. Dispõe sobre a qualificação de pessoas jurídicas de direito privado, sem fins lucrativos, como Organizações da Sociedade Civil de 
Interesse Público, institui e disciplina o Termo de Parceria, e dá outras providências. Disponível em: <http://www.planalto.gov.br/ccivil 03/leis/19790.htm>. Acesso em: 27 nov. 2019. BRASIL. Lei no 10.406, de 10 de janeiro de 2002. Institui o Código Civil. Disponível em: $<$ http://www.planalto.gov.br/ccivil 03/leis/2002/110406.htm>. Acesso em: 27 nov. 2019. BRASIL. Lei $\mathbf{n}^{\mathbf{0}} \mathbf{1 0 . 8 2 5}$, de 22 de dezembro de 2003. Dá nova redação aos arts. 44 e 2.031 da Lei no 10.406, de 10 de janeiro de 2002, que institui o Código Civil. Disponível em: $<$ http://www.planalto.gov.br/ccivil 03/leis/2003/L10.825.htm>. Acesso em: 27 nov. 2019. BRASIL. Lei no 13.019, de 31 de julho de 2014. Estabelece o regime jurídico das parcerias entre a administração pública e as organizações da sociedade civil, em regime de mútua cooperação, para a consecução de finalidades de interesse público e recíproco, mediante a execução de atividades ou de projetos previamente estabelecidos em planos de trabalho inseridos em termos de colaboração, em termos de fomento ou em acordos de cooperação; define diretrizes para a política de fomento, de colaboração e de cooperação com organizações da sociedade civil; e altera as Leis nºs 8.429, de 2 de junho de 1992, e 9.790, de 23 de março de 1999. Disponível em: <http:// www.planalto.gov.br/ccivil 03/ Ato2011-2014/2014/Lei/L13019.htm>. Acesso em: 27 nov. 2019. BRASIL. Lei $\mathbf{n}^{\circ}$ 13.102, de 26 de fevereiro de 2015. Altera a Lei $\mathrm{n}^{-}$13.019, de 31 de julho de 2014, que estabelece o regime jurídico das parcerias voluntárias, envolvendo ou não transferências de recursos financeiros, entre a administração pública e as organizações da sociedade civil, em regime de mútua cooperação, para a consecução de finalidades de interesse público; define diretrizes para a política de fomento e de colaboração com organizações da sociedade civil; institui o termo de colaboração e o termo de fomento; e altera as Leis n ․․ 8.429, de 2 de junho de 1992, e 9.790, de 23 de março de 1999. Disponível em: <http://www.planalto.gov.br/ ccivil 03/ Ato2015-2018/2015/Lei/L13102.htm>. Acesso em: 27 nov. 2019.

BURITY, J. Organizações religiosas e ações sociais: entre as políticas públicas e a sociedade civil. Revista Anthropológicas, v. 18, n. 2, p. 7-48, 2007.

BURRIIT, R. L.; HAHN, T.; SCHALTEGGER, S. Towards a comprehensive framework for environmental management accounting - links between business actors and environmental management accounting tools. Australian Accounting Review, v. 12, n. 27, p. 39-50, 2002.

CHENHALL, R. H. Management control systems design within its organizational context: findings from contingency-based research and directions for the future. Accounting, organizations and society, v. 28, n. 2, p. 127-168, 2003.

CHENHALL, R. H.; LANGFIELD-SMITH, K. Adoption and benefits of management accounting practices: an Australian study. Management Accounting Research, v. 9, n. 1, p. 1-19, 1998.

DIMAGGIO, P. J.; POWELL, W. W. The iron cage revisited: institutional isomorphism and collective rationality in organizational fields. American Sociological Review, v. 48, n. 2, p. 147-160, 1983.

ECKERD, A.; MOULTON, S. Heterogeneous roles and heterogeneous practices: understanding the adoption and uses of nonprofit performance evaluations. American Journal of Evaluation, v. 32, n. 1, p. 98-117, 2010.

ELSTUB, S. Participation. in: TAYLOR, R. Third sector research. Springer, 2010.

ESPEJO, M. M. S. B. Perfil dos atributos do sistema orçamentário sob a perspectiva contingencial: uma abordagem multivariada. 2008. 216 f. Tese (Doutorado em Ciências Contábeis) - Universidade de São Paulo, 2008. 
FRANÇA FILHO, F. C. D. Definindo gestão social. In: ENCONTRO NACIONAL DE PESQUISADORES EM GESTÃO SOCIAL, 1., 2007, Juazeiro do Norte. Anais... Juazeiro do Norte, 2007. FREEMAN, R. Edward. Strategic management: a stakeholder approach. Cambridge University Press, 1984.

GABIONETTA, S. L. Uma pesquisa sobre o uso de instrumentos de contabilidade gerencial por empresas listadas na revista eletrônica Forbes 2000. 2011. 146 f. Dissertação (Mestrado em Ciências Contábeis e Atuariais) - Pontifícia Universidade Católica de São Paulo, São Paulo, 2011.

GIL, A. C. Como elaborar projetos de pesquisa. São Paulo: Atlas, 2002

HARROW, J. Philanthropy. in: TAYLOR, R. Third sector research. Springer, 2010.

IBGE. As fundações privadas e associações sem fins lucrativos no Brasil em 2010. Brasília: Instituto Brasileiro de Geografia e Estatística, 2012.

INSTITUTO FONTE. Construindo o eco-mapa. Disponível em: <http://www.Institutofonte. org.br/sites/default/files/cap02_6_Fazer\%20um\%20(ecomapa)\%20de\%20interessados_InstitutoFonte.pdf>. Acesso em: 22 maio 2016.

INTERNATIONAL FEDERATION OF ACCOUNTANTS. Definition of management accounting. Disponível em: http://www.imanet.org/docs/default-source/research/sma/definition-of-mangement-accounting.pdf?sfvrsn=2> Acesso em: 22 jun. 2016.

IUDÍCIBUS, S. D. Teoria da contabilidade: evolução e tendências. Revista de Contabilidade do Mestrado em Ciências Contábeis da UERJ, v. 17, n. 2, p. 9, 2012.

JORDAN, L. Mechanisms for NGO accountability. Berlin: Global Public Policy Institute, 2005. LANDIM, L. Múltiplas identidades das ONGs. In: HADDAD, S. (Ed.). ONGs e Universidades: desafios para a cooperação na América Latina. São Paulo: Fundação Petropolis, 2002.

LAWRENCE, P.; LORSH, J. As empresas e o ambiente. Petrópolis: Vozes, 1973.

MATHEWS, M. R. The development of social and environmental accounting research 1995-2000. Disponível em: <http://www.massey.ac.nz/massey/fms/Colleges/College\%20of\%20 Business/School\%20of\%20Accountancy/Documents/Discussion\%20Papers/205.pdf >. Acesso em: 02 jun. 2016.

MCLELLAN, J. D.; MOUSTAFA, E. An exploratory analysis of management accounting practices in the Arab Gulf Cooperative countries. Journal of Islamic Accounting and Business Research, v. 4, n. 1, p. 51-63, 2013.

MILLER-MILLESEN, J. L. Understanding the behavior of nonprofit boards of directors: a theory-based approach. Nonprofit and Voluntary Sector Quarterly, v. 32, n. 4, p. 521-547, 2003. MINTZBERG, H.; AHLSTRAND, B.; LAMPEL, J. Safári da estratégia. Bookman, 2009.

MOOK, L. Social Accounting. In: TAYLOR, R. (Ed.). Third sector research: Springer, 2010.

MOORE, M. H. Managing for value: organizational strategy in for-profit, nonprofit, and governmental organizations. Nonprofit and Voluntary Sector Quarterly, v. 29, n. suppl 1, p. 183-208, 2000.

NASCIMENTO, A. R.; JUNQUEIRA, E.; MARTINS, G. A. Pesquisa acadêmica em contabilidade gerencial no Brasil: análise e reflexões sobre teorias, metodologias e paradigmas. Revista de Administração Contemporânea, v. 14, n. 6, p. 1113-1133, 2010.

OLAK, P. A.; NASCIMENTO, D. T. Contabilidade para entidades sem fins lucrativos (terceiro setor): inclui capítulos sobre contabilidade por fundos. Atlas, 2010. 
PAPASPYROPOULOS, K. G. et al. Challenges in implementing environmental management accounting tools: the case of a nonprofit forestry organization. Journal of Cleaner Production, v. 29-30, p. 132-143, 2012

PAVLATOS, O.; KOSTAKIS, H. Management accounting practices before and during economic crisis: evidence from Greece. Advances in Accounting, v. 31, n. 1, p. 150-164, 2015.

PELEGRINI, A. V. O processo de modularização em embalagens orientado para a customização em massa: uma contribuição para a gestão do design. 2005. 50 f. Dissertação (Mestrado em Engenharia Mecânica) Universidade Federal do Paraná, Curitiba, 2005.

PORTER, M. E. Competitive strategy: techniques for analyzing industries and competitors. Simon and Schuster, 1980.

PUTNAM, Robert D. Comunidade e democracia: a experiência da Itália moderna. Rio de Janeiro: FGV, 2002.

GODOY, J. G. V.; RAUPP, F. M. Uso de artefatos de contabilidade gerencial em organizações sem fins lucrativos. Sociedade, Contabilidade e Gestão, v. 12, n. 3, p. 70-87, 2017.

RAGINS, E. J.; GRECO, A. J. Customer relationship management and e-business: more than a software solution. Review of Business, v. 24, n. 1, p. 25-30, 2003.

SALAMON, L. M.; ANHEIER, H. K. Social Origins of Civil Society: explaining the Nonprofit Sector Cross-Nationally. Voluntas, v. 9, n. 3 p. 213-248, 1998.

SCHEFER, L. F. N. Governança no Instituto Padre Vilson Groh: sistematização de experiências de empoderamento. 2014. 384 f. Dissertação (Mestrado em Administração) - Universidade do Estado de Santa Catarina, Florianópolis, 2014.

SOLDEVILA, P.; OLIVEIRAS, E. Management control in non-profit organizations: the case of the associations of economists in Spain. 2000. Disponível em: < https://papers.ssrn.com/ sol3/papers.cfm?abstract id=311522>. Acesso em: 27 nov. 2019.

SOUTES, D. O. Uma investigação do uso de artefatos da contabilidade gerencial por empresas brasileiras. 2006. 116p. Dissertação (Mestrado em Ciências Contábeis) - Universidade de São Paulo, São Paulo, 2006.

STONE, M. M.; BIGELOW, B.; CRITTENDEN, W. Research on strategic management in nonprofit organizations synthesis, analysis, and future directions. Administration \& Society, v. 31, n. 3, p. 378-423, 1999.

VIEIRA, R. Produção científica brasileira sobre terceiro setor: uma análise bibliométrica e cienciométrica baseada no Banco de Teses da CAPES. 2011. 168 f. Dissertação (Mestrado em Ciência da Informação) - Universidade Federal de Santa Catarina, Florianópolis, 2011.

Recebido em: 11-5-2019

Aprovado em: 16-12-2019

Avaliado pelo sistema double blind review.

Editor: Coordenação do PPGA/UMESP

Disponível em http://mjs.metodista.br/index.php/roc 